\title{
Effects of feeding angles and cutting speeds of a mower knife with serrated edges on the pulverization of sweet potato vines
}

\begin{abstract}
A study was conducted to test the effects of three different speeds of 1830, 2066 and 2440 rpm of a mower knife with serrated edges and two different feeding angles of $45^{\circ}$ and $90^{\circ}$ on the pulverization of sweet potato vines. The results indicated that all the treatments were significant at $99 \%$ significance level for the pulverized percentage of sweet potato vines remaining on the sieve. The best result was for the $45^{\circ}$ feeding angle with lowest vine pulverized percentage of $47.20 \%$. The second speed of $2066 \mathrm{rpm}$ had the finest vine pulverized percentage of $57.47 \%$. The best performance for overlapping effect between feeding angle and speed of mower was achieved by the $45^{\circ}$ feeding angle and a mower speed of $1830 \mathrm{rpm}$ resulting in an average percentage of $44.45 \%$ of pulverized vines.
\end{abstract}

Keyword: Chopping; Feeding angle; Mower; Slasher; Speed; Sweet potato 